\title{
The effects of light pollution on biological rhythms of birds: an integrated, mechanistic perspective
}

Davide M. Dominoni $1, *$

Phone 0044-7871548151

Email davide.dominoni@glasgow.ac.uk

${ }^{1}$ Institute of Biodiversity, Animal Health and Comparative Medicine, University of Glasgow, Glasgow, UK

\section{Abstract}

Light pollution is considered a threat for biodiversity given the extent to which it can affect a vast number of behavioral and physiological processes in several species. This comes as no surprise as light is a fundamental, environmental cue through which organisms time their daily and seasonal activities, and alterations in the light environment have been found to affect profoundly the synchronization of the circadian clock, the endogenous mechanism that tracks and predicts variation in the external light/dark cycles. In this context, birds have been one of the most studied animal taxa, but our understanding of the effects of light pollution on the biological rhythms of avian species is mostly limited to behavioral responses. In order to understand which proximate mechanisms may be affected by artificial lights, we need an integrated perspective that focuses on light as a physiological signal, and especially on how photic information is perceived, decoded, and transmitted through the whole body. The aim of this review is to summarize the effects of light pollution on physiological and biochemical mechanisms that underlie changes in birds' behavior, highlighting the current gaps in our knowledge and proposing future research avenues. 


\section{Keywords}

Light pollution

Circadian rhythms

Annual rhythms

Chronodisruption

Melatonin

Deep brain photoreceptors

ipRGCs

Communicated by E. Matthysen.

\section{Introduction}

The last revision of the World Urbanization Prospects, published by the United Nations, has highlighted that more than $50 \%$ of the human population now lives in cities (IUCN 2012). Moreover, urban areas are one of the fastest growing land cover type, which substitutes natural as well as agricultural landscapes with artificial buildings, infrastructures, and anthropogenic stimuli such as light and noise. In particular, the presence of artificial lights is one of the most peculiar characteristics accompanying urban sprawl and more in general human domination of the Earth. In developed countries, very few places can be considered free of light pollution (Cinzano et al. 2000). If the consequences for activities such as stargazing are evident (Falchi et al. 2011 ), the same cannot be stated for wild organisms and the ecological systems they are part of. However, the last decade has seen a boost of interest into the ecological consequences of light pollution (Rich and Longcore 2006; Gaston et al. 2013), which the symposium "Light in the darkness: how does artificial night lighting influence bird behavior and ecology?" at the 26th IOC in Tokyo, Japan, perfectly exemplifies.

In birds, besides collision with artificially lit structures (Longcore et al. 2013 ), one of the most reported effects of light pollution is the shift in temporal behavior. Several studies have highlighted variation in daily as well as in seasonal rhythms of different bird species (Miller 2006b; Kempenaers et al. 2010; Nordt and Klenke 2013; Dominoni et al. 2014), although other environmental stimuli proper of urban areas might have confounded these 
results. Recently, quasi-experimental approaches in the field (Titulaer et al. 2012; Da Silva et al. 2014) and controlled experiments under laboratory conditions (Schoech et al. 2013; Dominoni et al. 2013b) have tested specific hypotheses about the effects of light at night on the daily and seasonal cycles of birds, which have included investigations on the physiological mechanisms underpinning the temporal responses of birds to light at night. Because light is the most important synchronizer of the avian circadian clock (Berson et al. 2002 ) and a countless number of physiological process are under circadian control (Foster and Kreitzmann 2004), changes in the light environment at night are likely to affect the expression of several biological functions. In this review, I will first stress the importance of light as physiological signal, by reviewing our knowledge of avian photoreception and non-visual encoding of light and by focusing on how light synchronizes circadian and seasonal rhythms. I will then summarize the evidence of changes in daily and seasonal organization of activities associated with light pollution, with a particular focus on the physiological pathways that have been found to be affected. Last, I will outline other physiological and molecular processes that are at present overlooked, but that could play a pivotal underlying role in the response of birds to light pollution.

\section{Avian photoreception}

Birds possess a wide range of photoreceptors located in several tissues, such as the retina of the eye, the brain, and the pineal gland. All of these photoreceptors use opsin-based photopigments to detect and transduce light. Opsins are a group of $\mathrm{G}$ protein-coupled receptors that can change their conformation from a resting state to a signalling state upon light absorption. Light stimulates the activation of the $G$ protein, producing a signalling cascade known as phototransduction (Doyle and Menaker 2007).

The best known photoreceptors are the rods and cones located in the retina [reviewed in (Peirson et al. 2009)]. Rods mediate visual response in dim light and are very sensitive to light stimuli, but provide low-resolution image forming. They contain a specific opsin $O p n 2$, which is the best characterized vertebrate opsin. In contrast, cones are used to create images in bright light and are, therefore, less sensitive to small changes in light levels, but mediate the formation of very high resolution images. Cones operate through a 
separate opsin, Opn1, which comes in different subclasses depending on their spectral sensitivity. The information collected by rods and cones is processed by inner retinal neurons (retinal ganglion cells, RGCs) before reaching the brain through the optic nerve.

Few of these RGCs are also photosensitive, and are denoted as intrinsically photoreceptive retinal ganglion cells (ipRGCs). ipRGCs project to all major parts of the brain and are especially important for non-visual responses, such as the expression of circadian rhythms, although rods and cones can also contribute to such responses. This specific set of ganglion cells decode light through the action of a particular opsin, melanopsin, termed Opn4 (Peirson et al. 2009; Lucas et al. 2014). In contrast to mammals, birds possess two different subclasses of melanopsins, Opn4x and Opn4m (Bellingham et al. 2006). The firing response of these photoreceptors increases depending on light irradiance, but melanopsins are much less photosensitive than rods and cones. That is, a higher threshold level of light intensity has to be reached to engage melanopsins. Melanopsin response peaks at $480 \mathrm{~nm}$ (Bellingham et al. 2006), but because non-visual responses to light are mediated not only by ipRGCs, but also by rod and cones, to describe the spectral sensitivity of such responses is not trivial. In mammals, it seems that circadian responses peak between 440 and $490 \mathrm{~nm}$ (Berson et al. 2002), but such information is still missing from avian species.

Another important site of photoreception in avian species is the pineal gland. Indeed, conversely to mammals, where the pineal gland has a merely secretory role, but it is not photosensitive, the avian pineal contains its own photoreceptor, pinopsin ( $P$-opsin), with a spectral peak between 460 and $470 \mathrm{~nm}$ (Max et al. 1995). Because of its intrinsic sensitivity to light, the pineal gland plays a pivotal role in the regulation of avian circadian rhythms (Gwinner and Brandstätter 2001).

Last, a set of deep-brain photoreceptors has been recently characterized in chickens. Although the existence of such photoreceptors was long suggested, their structure and property were still elusive. Vertebrate-ancient (VA) opsin has now been found in the chicken hypothalamus, with an action spectra that peaks at $460 \mathrm{~nm}$ (Halford et al. 2009; Davies et al. 2012). These photoreceptors seem to be involved in the regulation of seasonal biology and 
explain why early studies found that blinded birds were still able to undergo complete seasonal rhythms of gonadal growth and regression.

\section{Light and circadian rhythms}

The rhythms of life on Earth are regulated by sunlight. Almost all organisms on our planet synchronize their daily activities based on the information provided by the sun (Foster and Kreitzmann 2004). Some have evolved to be diurnal, some nocturnal, and some others have learned to exploit the twilight phases that separate day and night. In order to maximize fitness and, therefore, to adapt to the environment in which they live, all organisms have to ensure to be active at the right time during $24 \mathrm{~h}$ in order to find food and minimize the risk of predation. As a matter of fact, there is striking convergence between daily cycles of light and darkness and an animal's activity patterns, of which birds are among the best examples (Aschoff and von Goetz 1989). However, organisms do not just respond to external light stimuli, but they have evolved an endogenous mechanism, called the circadian rhythm, that helps them to track temporal changes in the light environment and anticipate these changes when needed. A key feature that defines circadian rhythms and distinguishes them from other rhythmic processes is that they persist under constant light conditions (normally constant darkness or constant dim light) (Aschoff 1984). That is, if an animal is deprived of any information about what time of the day is, it will still express clear rhythms of behavior, physiology, and biochemical processes. However, these rhythms will not exactly be of $24 \mathrm{~h}$, and that is why they are called circadian ( $\operatorname{circa}=$ approximately, dian = a day). In a similar way, circannual rhythms represent the endogenous organization of annual cycles (Gwinner 1986). Birds have been very important models for the study of circannual rhythmicity, and although the proximate mechanisms that regulate these cycles are still very elusive, birds offer some of the best examples of circannual rhythms studied so far (Gwinner 2003). These endogenously produced rhythms mean little if they are not synchronized, or entrained, to the external environment. In most taxa, including birds, light is the most potent synchronizer of circadian and circannual rhythms. But how does light tune the internal rhythms of birds?

As I highlighted in the previous section, birds possess a variety of 
photoreceptors that are involved in circadian timing. In particular, the eyes, the hypothalamus, and the pineal gland are three independent structures that are sensitive to light and that are involved in the expression and regulation of circadian rhythms. Because of this, the circadian system of birds is more complex compared to that of mammals, which, however, has been much better characterized. The greatest difference is in the degree of involvement of the separate components of the circadian systems. In mammals, the master circadian clock is located in a specific set of cells of the hypothalamus, the suprachiasmatic nuclei (SCN) (Menaker et al. 1997), which receives light stimuli from a subset of ganglion cells called ipRGCs (see above) (Berson et al. 2002), while the pineal gland is less involved in circadian timing. In birds, non-visual light stimuli are mainly received in the retina, the hypothalamus (via the retinal hypothalamic tract, RHT), and in the pineal gland (Gwinner and Brandstätter 2001). At present, it is still unclear how this information is integrated between the different components of the avian central circadian system (Cassone 2013), but it is evident that the pineal gland plays a much bigger role than it does in mammals. One model, the "neuroendocrine loop", suggested that the retina, pineal gland, and an SCNlike structure in the hypothalamus all contain "damped" oscillators that are capable of self-producing oscillation only if photic or endocrine stimuli are present (Cassone and Menaker 1984). Instead, the "internal-resonance" model proposed that the pineal gland and the SCN sustain and stabilize each other through the expression of independent circadian outputs, such as the cyclic expression of specific clock genes in the SCN and the release of melatonin from the pineal gland (Gwinner 1989). Communication between the SCN and peripheral clocks in birds is accomplished via a combination of humoral signals and direct neural connections, which are far less understood in birds than in mammals (Cassone 2013). Humoral signals directly affect hypothalamic function, while neural outputs project to the central nervous systems and peripheral sites, impacting a broad range of peripheral physiological functions, including that of the pineal gland. The pineal gland acts as a key site of light signal transduction, transforming photic information into a diffusible signal via the production and secretion of melatonin directly into the blood and cerebrospinal fluid (Gwinner et al. 1997). The pineal gland releases melatonin at night, but its production is suppressed during the day by sunlight, conferring melatonin an important role as master circadian 
hormone. In addition, tissues that express melatonin receptors, such as the song control system (see below), are directly affected by changes in melatonin secretion (Cassone et al. 2009).

The molecular mechanisms governing the expression of avian circadian rhythms are much less understood in birds than in mammals. In mammals, light stimulation of non-visual photoreceptors results in excitatory signaling to the SCN where a transcriptional-translational feedback loop in gene expression is initiated (Dunlap 1999). Clock and Bmall protein products form a heterodimer that binds the promoters of Per and Cry to enhance their transcription. The protein products, PER and CRY, then form heterodimers in the cytoplasm that translocate back into the nucleus to interact with the CLOCK:BMAL1 complex to inhibit their own transcription. This results in "positive" (Clock and Bmall) and "negative" (Per and Cry) arms of the circadian feedback loop, which reciprocally operate with a period of $\sim 24 \mathrm{~h}$. This feedback loop is expressed in most cells throughout the body, although phase differences do occur (Storch et al. 2002). Orthologs of mammalian clock genes have been identified in birds and investigations within the avian hypothalamus have characterized rhythms in circadian gene expression that persist under constant conditions, similar to mammals (Abraham et al. 2003). Recently, functional genomic analyses of the chicken retina and pineal gland highlighted that the temporal expression of clock genes varies between these two organs (Bailey et al. 2004; Karaganis et al. 2008). In particular, the retina seems to lack a CLOCK rhythm. These studies have highlighted inconsistencies between the avian and mammalian model of circadian genes expression, which call for further studies into the molecular basis of avian circadian rhythms.

\section{The proximate mechanisms underlying avian seasonal biology}

While our knowledge of the circadian system of birds has made great steps forwards in the last two decades, insights into how avian circannual and annual rhythms are regulated is still very vague. Early pioneering studies have demonstrated persisting rhythms of annual events in birds kept under constant light conditions for years (Gwinner 1986). At present, while birds remain one great model system to investigate circannual rhythms, we 
understand very little about the physiological and molecular mechanisms that underlie avian circannual rhythmicity (but see Wikelski et al. 2008). On top of this uncertainty, the regulation of annual cycles has also been quite a mystery, at least until the end of the last century. In the last two decades, however, significant advances in our understanding of how (1) photic information is integrated for seasonal reproduction and (2) the role of melatonin in annual cycles, have clarified some of this uncertainty.

As suggested by early studies, birds do not need eyes to develop a reproductive state, suggesting that the photoreceptors involved in seasonal biology are located elsewhere (Rowan 1938). This location has remained a mystery for a long time, but a recent study has finally identified vertebrateancient (VA) opsins as photoreceptors in the deep brain (Halford et al. 2009). These opsins have an action spectrum that peaks around $460 \mathrm{~nm}$, in accordance with the results from previous works that have investigated the wavelength of light at which avian photoperiodic response is maximal (Foster et al. 1985 ). These deep brain photoreceptors project to a set of cells called pars tuberalis, where thyrotropin (TSH) is produced in response to lengthening days, which in turn stimulates the release of thyroid hormones and neurohormones into the hypothalamus, and consequent activation of the hypothalamus-pituitary-gonadal (HPG) axis (Wyse and Hazlerigg 2009).

Another aspect of avian seasonal biology that has long remained elusive is the role of melatonin in seasonal reproduction. While in mammals melatonin provides a representation of daylength that is used to stimulate reproductive growth and regression (Arendt 1998), experiments conducted in birds have always failed to reveal a direct involvement of melatonin in the stimulation of gonadal growth (reviewed in Bentley 2001). However, in the last two decades melatonin has been suggested to affect seasonal breeding in at least three ways, all of which sees the participation of the same thyroid-dependent mechanism mentioned above. First, melatonin can stimulate cell-mediated immune responses typical of winter, while increasing daylength dampens the immune system during reproduction (Bentley et al. 1998). Second, melatonin can directly affect the plasticity of the avian song control system (Bentley et al. 1999; Cassone et al. 2008). In particular, melatonin receptors have been identified in the forebrain song control nucleus, Area X. These melatonin receptors are downregulated during breeding and upregulated in winter, when 
they are stimulated by increasing daylength (Bentley et al. 1999). Last, melatonin has been shown to stimulate the release of gonadotropic-inhibitory hormone $(\mathrm{GnIH})$ from the avian hypothalamus, a process that inhibits seasonal breeding (Tsutsui et al. 2006). All together, these results indicate that melatonin can still play an important role in the regulation of avian reproduction. As melatonin release from the pineal gland is directly dependent on light intensity, increasing daylength in spring have a strong effect on melatonin production and, therefore, indirectly, on reproductive state.

\section{Light pollution and daily cycles}

The modification of birds' daily rhythms is one of the most known ecological effects of light pollution. Several songbird species have been found to modify their time of singing in light polluted areas in different geographical regions. The effect is strongest for some naturally early singing species: European robin (Erithacus rubecola) (Fuller et al. 2007; Kempenaers et al. 2010; Da Silva et al. 2014), American robin (Turdus migratorius) (Miller 2006a), Common blackbird (Turdus merula) (Kempenaers et al. 2010; Dominoni et al. 2014; Da Silva et al. 2014), and Great tit (Parus major) (Kempenaers et al. 2010; Da Silva et al. 2014). These species sometimes sing truly at night. The effects are more moderate in other species, such as the song thrush (Turdus philomelos) (Da Silva et al. 2014) and the Blue tit (Cyanistes caeruleus) (Kempenaers et al. 2010; Da Silva et al. 2014). While all of them have reported an earlier onset of dawn song, few have also shown a later offset of activity in the evening (Dominoni et al. 2014; Da Silva et al. 2014) and even singing behavior in the middle of the night (Fuller et al. 2007). However, these studies were limited in the sense that they have reported only the time at which the first (or last) active event (singing or locomotor activity) was heard from a particular individual and/or species, but information of their activity patterns throughout the $24 \mathrm{~h}$ is largely lacking. A study that manipulated nocturnal light levels by placing LED lights on top of great tits' nest boxes revealed that chick provisioning rhythms were affected by the light treatment (Titulaer et al. 2012). Interestingly enough, this manipulation failed to affect the onset and offset of daily activity, although the experiment did not record dawn and dusk song, but rather dealt with start and end of foraging in great tits, which usually occur after sunrise and before 
sunset (i.e. at very high levels of natural light), and used an LED light of weak intensity.

Although these studies are very informative, most of them are biased by the presence of other environmental factors that covary with light pollution in the city, such as noise, anthropogenic food supply, and temperature. Only a few studies have tried to overcome this limitation in the field to at least separate the effects of noise and light, while controlling for ambient temperature (Kempenaers et al. 2010; Da Silva et al. 2014). These have shown that light pollution can clearly alter the onset and offset of daily singing in a variety of species, and that the annual development of dawn and dusk chorus is accelerated under artificial lights (Da Silva et al. 2015). In addition, Kempenaers and colleagues have demonstrated that artificial lights not only advance dawn song in the blue tit, but early singing associated with lights was positively correlated with the amount of extra-pair offspring that males were able to sire, hinting at potential reproductive consequences of light pollution (Kempenaers et al. 2010). Recent studies from the same group have expanded this previous work, showing that females advanced their morning onset of activity during the breeding season when their nest-boxes were artificially illuminated (Schlicht et al. 2014).

Laboratory studies have experimentally demonstrated that light at night is a major source of modification of daily activity patterns, independently of any other environmental factor. For instance, my own work has shown that male European blackbirds captured from urban and rural locations strongly advanced their onset of morning activity when exposed to realistic levels of light intensity at night (0.3 lux) in captivity (Dominoni et al. 2013b). The effect size of this manipulation was approximately $2 \mathrm{~h}$ of advanced dawn song in the morning, an effect that explains most of the variation observed in the field. The limitation of this study was that the measurements of dawn song were based on only on 12 data points, i.e. 1 day per month during 6 months, with one measurement being carried out in the lighted room and the other one in the dark room. This result may, therefore, strongly be influenced by the presence of just one very early singer in the lighted room. However, in a subsequent work, I have shown that the early morning activity in captive blackbirds during the breeding season was related at the individual level to the plasma concentration of melatonin. Indeed, light at night 
suppressed melatonin levels in the morning, and this change was associated with earlier onset of individual activity (Dominoni et al. 2013c). A similar study has tested the effect of low levels of light at night ( 0.3 lux) on the melatonin profiles of Florida scrub-jays (Aphelocoma coerulescens), but has surprisingly shown opposite results compared to my work on blackbirds: jays that were exposed to light at night showed higher levels of melatonin than animals exposed to normal light:dark cycles (Schoech et al. 2013). Future studies should try to explore the relationship between light intensity and physiology, especially melatonin, in the wild. In this context, recently established experimental facilities in the field can definitely add important perspectives to the research done so far (Spoelstra et al. 2015).

Studies on the ecological effects of light pollution have traditionally measured average light intensity from limited locations within the area of study. Although these measurements give an indication of the overall brightness of the area where animals live, they provide little information about the relationship between light and activity at the individual level. My research on European blackbirds has tried to overcome this limitation by placing micro light loggers on the backs of individual birds, while at the same time using automated radio-telemetry to infer the activity patterns of the same animals. Surprisingly, the amount of light intensity that blackbirds are exposed to in the urban study site were very low (0.2 lux) compared to what I measured underneath the street lamps present in the same area (6 lux) (Dominoni et al. 2013b). This might suggest that blackbirds actively choose to roost in dark areas, while exploiting the presence of artificial lights in the late evening and early morning. Indeed, the individual exposure to light at night was related to the onset and offset of activity in the morning and evening: the more an animal was subjected to light pollution, the more it tended to extend its activity period into the night (Dominoni et al. 2014). A subsequent analysis of the same dataset has investigated whether blackbirds in the city are exposed to a longer day length than forest conspecifics. I used the data on the onset and offset of activity to calculate light-intensity thresholds that defined the onset and offset of the subjective (or perceived) day for all birds, and then applied the thresholds to the light intensity timeseries of each individual bird to examine when these thresholds were passed in the morning and evening. This analysis revealed that urban blackbirds are 
exposed on average to a 49 min longer daylength than birds living in nearby forest areas, a result that conforms to the average extended activity time found in the same birds (Dominoni and Partecke 2015).

\section{Light pollution and annual cycles}

An ample body of evidence has suggested that several bird species advance their timing of reproduction in relation to urbanization. Some studies have investigated changes in reproductive physiology, although shifts in egglaying date were mostly reported (Chamberlain et al. 2009; Deviche and Davies 2013).

In the USA, Florida scrub-jays and desert species such as Albert's towhee (Melozone aberti) and Curve-billed thrasher (Toxostoma curvirostre) have been widely studied. In Europe, European blackbirds are one of the best examples of advanced reproductive physiology following urbanization. In these study species, reproductive physiology (gonadal development and reproductive hormones) have been found to peak a few weeks earlier in urban areas (Deviche and Davies 2013 ). Obviously, this tells little about the environmental factors driving such phenological shifts. Follow-up experiments on the Florida scrub-jays have suggested availability of anthropogenic food source (Schoech et al. 2004) as well as reduced stress (corticosterone levels in the plasma) (Schoech et al. 2009) in suburban jays as two potential mechanisms underlying early breeding in this population compared to wildland ones. In European blackbirds, I used the same aforementioned experimental set-up in the laboratory to test not only whether light pollution advances daily cycles of activity, but also its effects on the reproductive physiology. During the first reproductive year, blackbirds exposed to light at night developed their gonads 3 weeks earlier than birds held under dark nights. This difference was mirrored by an earlier peak in plasma testosterone levels and by an earlier onset of molt at the end of gonadal regression (Dominoni et al. 2013b). Unfortunately, the physiological mechanism behind such effect is still elusive. A possible link could be a reduction in melatonin due to light at night, but unfortunately melatonin was only measured during the second reproductive year, when birds exposed to light at night did not show any reproductive function. Indeed, in the second year of this study blackbirds held under light at night failed to develop their 
gonads, testosterone levels were at their baseline, and molt was interrupted (Dominoni et al. 2013d). It is possible that constant, chronic levels of dim light at night "trapped" blackbirds into a photorefractory state after the first gonadal cycle, but this hypothesis remains untested. As for the onset of dawn song, this light stimulation was able to explain most of the variation in timing of gonadal growth observed between rural and urban blackbirds in the wild (Partecke et al. 2005). It remains to be established, however, the exact physiological system upon which light at night may act in order to accelerate reproductive growth.

These findings on the physiology of reproduction accompany, although not always conform to, changes in egg-laying date. Indeed, several species, especially in Europe, have been shown to advance lay date in urban and suburban areas (Chamberlain et al. 2009; Deviche and Davies 2013 ). However, at present, only two studies tested the hypothesis that these shifts in lay date are caused by light pollution. Kempenaers and collaborators have shown a 2-day advance in lay date in blue tits that occupied territories closed to street lamps (Kempenaers et al. 2010). More recently, De Jong and colleagues experimentally altered light levels in eight forests across the Netherlands and showed a 5-day advanced in laying date of great tits (De Jong et al. 2015). The temporal discrepancy found between the effects of light at night on reproductive physiology and laying date suggests that while reproductive physiology of temperate avian species is mostly modulated by light (Dawson et al. 2001), and thus light pollution can have a stronger effect on it, laying date is a complex life-history decision that is regulated not only by photoperiod, but also by factors that reflect more the current environmental conditions, such as temperature and food abundance (Caro et al. 2013 ). A recent captive study on the relationship between gonadal growth and egg-laying date has shown very weak correlation between the two variables, highlighting that these are independent mechanisms that can be differentially affected by artificial lights (Schaper et al. 2012). It remains to be established how light at night affects reproductive timing. A likely mechanism is the stimulation of deep-brain photoreceptors (see above). As such receptors are more sensitive to wavelengths of light around the blue spectrum (Davies et al. 2012), artificial lights that are rich in these wavelengths are likely to have a stronger impact on the reproductive 
physiology of birds. Indeed, the same experiment from De Jong and collaborators cited above has also suggested that lay-date is less affected by the long wavelengths of red LED lights compared to blue and green LEDs (De Jong et al. 2015). Future studies should investigate this issue further, as their results could provide important scientific knowledge upon which to call for a re-assessment of the potential impact of different light sources on birds and more in general on wildlife, which will have great relevance for future policy-making strategies.

As for the effects of light pollution on daily cycles, we have a limited understanding of the fitness consequences of the phenological shifts recorded in birds breeding under artificial lights (but see De Jong et al. 2015). While early breeders are found to benefit from early access to better territories and food resources, this hypothesis is still largely untested in the context of light pollution. In addition, potential physiological costs may arise as a consequence of growing the reproductive system, an energetically expensive process, particularly when external conditions are still not optimal (Thomas et al. 2001; Metcalfe and Monaghan 2012).

\section{Future directions}

\section{The molecular ecology of light pollution}

In mammals, large parts of the genome are regulated in a circadian fashion. Indeed, around $10 \%$ of the genes show a circadian rhythm of expression (Eckel-Mahan et al. 2012). Such effects are mirrored by the circadian nature of many biochemical, physiological and behavioral processes, demonstrated in humans and model rodent species (Panda et al. 2002; Dallmann et al. 2012; Patel et al. 2012; Azzi et al. 2014). The molecular clockwork is well described in mammal species, and so is the integration of non-visual photic information by photoreceptors in the inner retina. Such detailed description of the mammalian circadian system has helped researchers interested in the effects of light pollution to predict the pathways through which light at night may affect circadian rhythms in mammals (Fonken and Nelson 2014). For instance, as the expression of the negative clock gene Per is normally low at night, light administered during the subjective night should significantly alter the pattern of Per expression and consequently affect other components of the 
circadian clock. Dim light at night ( $\sim 5$ lux $)$ has been shown to alter circadian clock gene expression of mice (Fonken et al. 2013a; Fonken and Nelson 2014 ) and Siberian hamsters (Bedrosian et al. 2013), including Bmal1, Perl, Per2, Cry1, Cry2, and Rev-Erb. These effects have been reported in both the $\mathrm{SCN}$ and the liver, with the latter associated with increased body weight independently of daily caloric intake (Fonken et al. 2013a).

In comparison to mammals, we know very little about the molecular mechanisms underpinning circadian rhythms in birds, although few studies and reviews have identified both similarities and differences (Bell-Pedersen et al. 2005). The widespread evidence that light at night can directly alter the expression of several clock genes in mammals calls for similar studies in wild birds. A recent work of mine has related variation in daily timing in citydwelling European blackbirds to the properties of the underlying circadian clock, which was shown to be faster but also more disrupted in urban areas (Dominoni et al. 2013a). As circadian disruption has been linked to impaired metabolic functions related to health (for instance, increase in body weight), there is an impelling need to understand whether similar effects are also found in birds, and how they might relate to other physiological processes that cross-talk with the circadian system. For instance, the immune system is a good candidate. The ability of animals, including birds, to respond to external parasites and pathogens greatly depends on the time of day. When circadian rhythms are disrupted, several immune responses become dampened (Arjona et al. 2012). Indeed, a number of studies on rodents have suggested that exposure to light at night is capable of reducing both innate and acquired immunity (Bedrosian et al. 2011; Fonken et al. 2012, 2013b). However, nothing is known about the effects of light at night on the immune system of wild birds, and this seems to be a promising research avenue (Fig. 1).

\section{Fig. 1}

How birds perceive and interpret light. In birds, photic information is captured by three different structures located in the skull, the retina, the pineal gland and the hypothalamus. Within each of these, different types of photoreceptors have been described. In the retina, two types of melanopsin, Opn4x, and Opn4 $\mathrm{m}$ receives light and project such information to the hypothalamus, where a circadian feedback loop of clock gene expression is synchronized depending on 
the external light:dark cycle. However, circadian rhythms are also regulated by the hormonal signals received by the pineal gland. The pineal contains its own photoreceptor, Pinopsin (P-opsin). Photic stimulation of such photoreceptor, usually by daylight, blocks the production of the hormone melatonin. Melatonin is in turn released at night and provides additional information to synchronize the hypothalamic circadian clock, an SCN-like structure that acts as central pacemaker. The hypothalamic clock does not just integrate circadian information, it contains another set of photoreceptors, termed VA-opsins, that are is directly sensitive to light and translates the photic signal into a cascade of neuropeptide and hormone production, which involves to a large extent the thyroid. This activates the hypothalamus-pituitary-gonadal axis which regulates gonadal growth and thus seasonal breeding. Recent findings suggest that melatonin could also play an important role in seasonal biology, mostly via regulating the seasonal growth of the song control systems (HVC, RA)

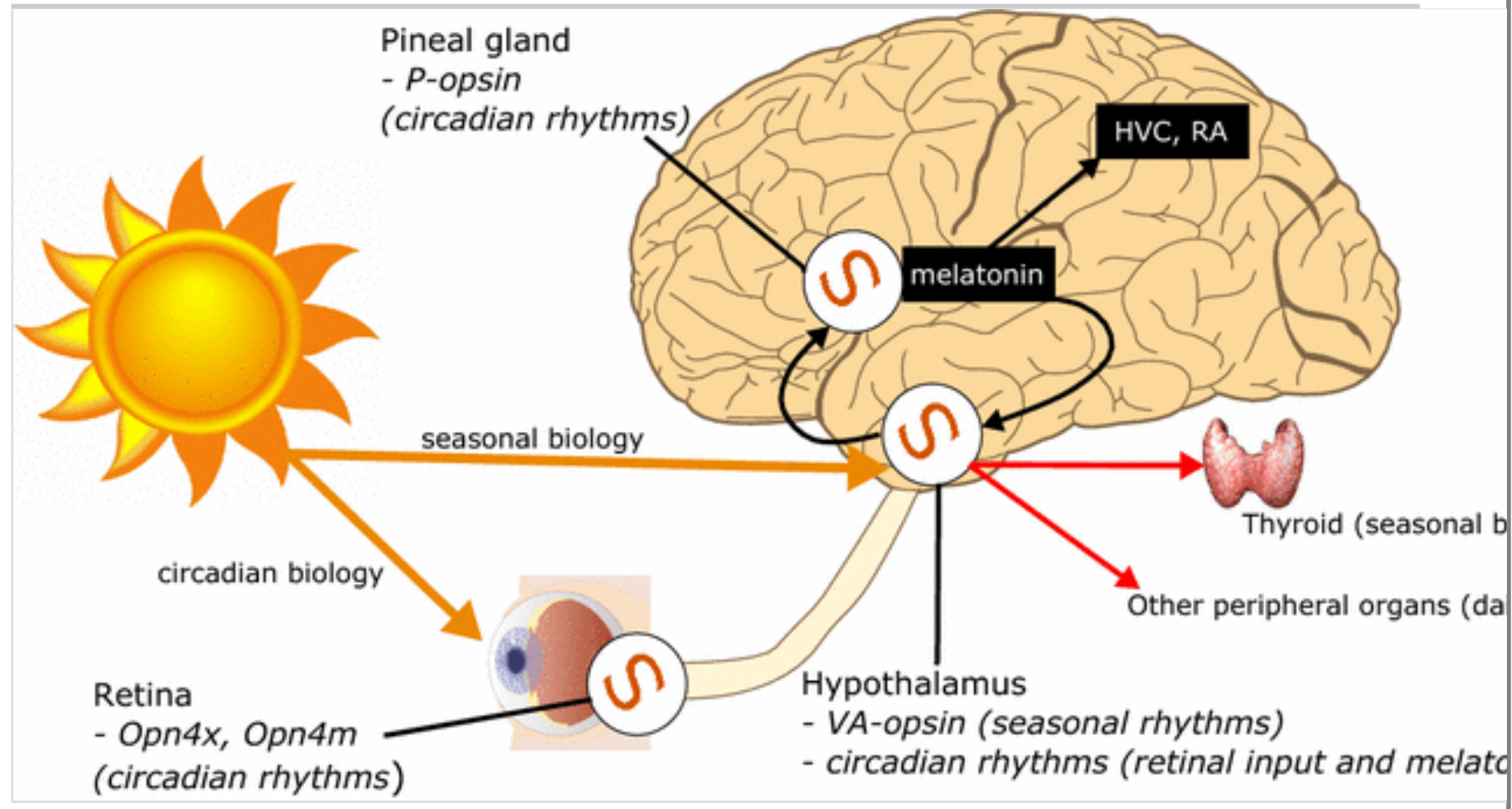

\section{Artificial lights and sleep}

At present, a largely overlooked aspect about the effects of light pollution on biological rhythms of birds is sleep. Sleep is a fundamental process of all organisms, and although its adaptive function is still largely elusive, recent findings suggest that sleep plays a vital role in "cleaning up" the brain from 
toxic metabolites accumulated during the active period (Xie et al. 2013). Because circadian rhythm, sleep, and light are deeply interconnected, light pollution may potentially have strong effects on sleep patterns of wild birds, as suggested by studies on humans (Archer et al. 2014). At present, however, we only have indirect estimates of such effects. The widespread evidence that light pollution can extend activity into the true night may suggest that sleep duration is reduced under light at night, but this might be compensated via more resting periods during the day. However, this disrupted pattern of sleep could resemble sleep properties of shift-workers and jet-lag, both of which have been associated with physiological and psychological side-effects (Rajaratnam and Arendt 2001; Kantermann et al. 2010). This hypothesis is of course largely speculative in the context of free-living birds, but studying sleep in the wild is a novel and promising research avenue, as highlighted by recent papers that have used state-of-the-art tools to record EEG on wild birds (Rattenborg et al. 2008; Lesku et al. 2012). It will be extremely interesting to apply such approaches to the study of urban birds and the effects of light pollution on their sleep behavior.

\section{Conclusions}

With the increasing body of work on the effects of light pollution on birds, it is becoming evident that several temporal aspects of physiology and behavior can be altered by artificial lights. While the proximate mechanisms underlying such effects are largely studied in humans and model rodent species, only a few studies have examined the mechanisms underpinning the effects of light at night on birds. To fill this gap, laboratory studies undoubtedly have benefits, as they allow an experimental approach limiting several biases that may arise from field investigations. However, it is also very important to understand whether the same proximate effects of light pollution are found in wild living birds, because that is where natural selection acts and thus where we can measure the real impact of artificial lights. I see the integration of controlled laboratory experiments and experimental manipulations of nightlight levels in the wild as the way forward that will allow us to understand not only the mechanisms through which light pollution affects the behaviour of wild birds, but also its ecological and fitness consequences. 


\section{Acknowledgments}

I would like to thank Prof. Bart Kempenaers and Dr. Caren Cooper for inviting me to present my research during the symposium they organized at the 26th IOC in Tokyo. I am thankful to Dr. Jesko Partecke for his illuminated guidance during my doctoral work. Much of my own data would have never been collected without his support, as well as the funding provided by the International Max Planck Institute for Ornithology. Many of the ideas that I developed during the last few years and that I present in this manuscript benefitted from the input and comments of many people, including Barbara Helm, Michaela Hau, Tim Greives, Martin Wikelski, Till Roenneberg, and Leonida Fusani.

\section{References}

Abraham U, Albrecht U, Brandstätter R (2003) Hypothalamic circadian organization in birds. II. Clock gene expression. Chronobiol Int 20:657669

Archer SN, Laing EE, Möller-Levet CS et al (2014) Mistimed sleep disrupts circadian regulation of the human transcriptome. Proc Natl Acad Sci USA 111:E682-E691. doi:10.1073/pnas.1316335111

Arendt J (1998) Melatonin and the pineal gland: influence on mammalian seasonal and circadian physiology. Rev Reprod 3:13-22

Arjona A, Silver A, Walker W, Fikrig E (2012) Immunity's fourth dimension: approaching the circadian-immune connection. Trends Immunol 33:607-612. doi:10.1016/j.it.2012.08.007

Aschoff J (1984) Circadian timing. Ann N Y Acad Sci 423:442-468

Aschoff J, von Goetz C (1989) Masking of circadian activity rhythms in canaries by light and dark. J Biol Rhythms 4:29.

doi:10.1177/074873048900400102

Azzi A, Dallmann R, Casserly A et al (2014) Circadian behavior is light- 
reprogrammed by plastic DNA methylation. Nat Neurosci 17:377-382. doi:10.1038/nn.3651

Bailey MJ, Beremand PD, Hammer R et al (2004) Transcriptional profiling of circadian patterns of mRNA expression in the chick retina. $\mathrm{J}$ Biol Chem 279:52247-52254. doi:10.1074/jbc.M405679200

Bedrosian TA, Fonken LK, Walton JC, Nelson RJ (2011) Chronic exposure to dim light at night suppresses immune responses in Siberian hamsters. Biol Lett 7:468-471

Bedrosian TA, Galan A, Vaughn CA et al (2013) Light at night alters daily patterns of cortisol and clock proteins in female Siberian hamsters. J Endocrinol 25:590-596

Bellingham J, Chaurasia SS, Melyan Z et al (2006) Evolution of melanopsin photoreceptors: discovery and characterization of a new melanopsin in nonmammalian vertebrates. PLoS Biol 4:e254. doi:10.1371/journal.pbio.0040254

Bell-Pedersen D, Cassone VM, Earnest D et al (2005) Circadian rhythms from multiple oscillators: lessons from diverse organisms. Nat Rev 4:121130. doi:10.1038/nrd1633

Bentley GE (2001) Unraveling the enigma: the role of melatonin in seasonal processes in birds. Microsc Res Tech 53:63-71

Bentley GE, Demas GE, Nelson RJ, Ball GF (1998) Melatonin, immunity and cost of reproductive state in male European starlings. Proc R Soc B Biol Sci 265:1191-1195. doi:10.1098/rspb.1998.0418

Bentley GE, Van't Hof TJ, Ball GF (1999) Seasonal neuroplasticity in the songbird telencephalon: a role for melatonin. Proc Natl Acad Sci USA 96:4674-4679. doi:10.1073/pnas.96.8.4674

Berson DM, Dunn FA, Takao M (2002) Phototransduction by retinal ganglion cells that set the circadian clock. Science 295:1070-1073. 
doi:10.1126/science. 1067262

Caro SP, Schaper SV, Hut RA et al (2013) The case of the missing mechanism: how does temperature influence seasonal timing in endotherms? PLoS Biol 11:e1001517. doi:10.1371/journal.pbio.1001517

Cassone VM (2013) Avian circadian organization: a chorus of clocks. Front Neuroendocrinol. doi:10.1016/j.yfrne.2013.10.002

Cassone VM, Menaker M (1984) Is the avian circadian system a neuroendocrine loop? J Exp Zool 232:539-549.

doi:10.1002/jez.1402320321

Cassone VM, Bartell PA, Earnest BJ, Kumar V (2008) Duration of melatonin regulates seasonal changes in song control nuclei of the house sparrow, Passer domesticus: independence from gonads and circadian entrainment. J Biol Rhythms 23:49-58. doi:10.1177/0748730407311110

Cassone VM, Paulose JK, Whitfield-Rucker MG, Peters JL (2009) Time's arrow flies like a bird: two paradoxes for avian circadian biology. Gen Comp Endocrinol 163:109-116. doi:10.1016/j.ygcen.2009.01.003

Chamberlain DE, Cannon AR, Toms MP et al (2009) Avian productivity in urban landscapes: a review and meta-analysis. Ibis 151:1-18 (Lond 1859)

Cinzano P, Falchi F, Elvidge CD, Baugh KE (2000) The artificial night sky brightness mapped from DMSP satellite operational Linescan system measurements. Mon Not R Astron Soc 318:641-657. doi:10.1046/j.13658711.2000.03562.x

Da Silva A, Samplonius JM, Schlicht E et al (2014) Artificial night lighting rather than traffic noise affects the daily timing of dawn and dusk singing in common European songbirds. Behav Ecol 25:1037-1047. doi:10.1093/beheco/aru103

Da Silva A, Valcu M, Kempenaers B (2015) Light pollution alters the 
phenology of dawn and dusk singing in common European songbirds. Philos Trans R Soc London Ser B

AQ3

Dallmann R, Viola AU, Tarokh L et al (2012) The human circadian metabolome. Proc Natl Acad Sci USA 109:2625-2629. doi:10.1073/pnas.1114410109

Davies WIL, Turton M, Peirson SN et al (2012) Vertebrate ancient opsin photopigment spectra and the avian photoperiodic response. Biol Lett 8:291-294

Dawson A, King VM, Bentley GE, Ball GF (2001) Photoperiodic control of seasonality in birds. J Biol Rhythms 16:365-380

De Jong M, Ouyang JQ, Da Silva A, et al (2015) Effects of nocturnal illumination on life history decisions and fitness in wild birds. Philos Trans R Soc Lond Ser B

Deviche P, Davies S (2013) Reproductive phenology of urban birds: environmental cues and mechanisms. In: Gil D, Brumm H (eds) Avian Urban Ecology: Behavioural and Physiological Adaptations, Oxford University Press, Oxford, UK, p 98-115.

$\mathrm{AQ4}$

Dominoni D, Partecke J (2015) Does light pollution alter the perception of daylength? A test using light loggers on European blackbirds (Turdus merula). Philos Trans R Soc Lond Ser B

Dominoni D, Helm B, Lehmann M et al (2013a) Clocks for the city: circadian differences between forest and city songbirds. Proc R Soc Lond B 280:20130593

Dominoni D, Quetting M, Partecke J (2013b) Artificial light at night advances avian reproductive physiology. Proc R Soc Lond B 280:20123017 
Dominoni DM, Goymann W, Helm B, Partecke J (2013c) Urban-like night illumination reduces melatonin release in European blackbirds (Turdus merula): implications of city life for biological time-keeping of songbirds. Front Zool 10:60. doi:10.1186/1742-9994-10-60

Dominoni DM, Quetting M, Partecke J (2013d) Long-term effects of chronic light pollution on seasonal functions of European blackbirds (Turdus merula). PLoS One 8:e85069. doi:10.1371/journal.pone.0085069

Dominoni DM, Carmona-Wagner EO, Hofmann M et al (2014) Individualbased measurements of light intensity provide new insights into the effects of artificial light at night on daily rhythms of urban-dwelling songbirds. J Anim Ecol 83:681-692. doi:10.1111/1365-2656.12150

Doyle S, Menaker M (2007) Circadian photoreception in vertebrates. Cold Spring Harb Symp Quant Biol 72:499-508. doi:10.1101/sqb.2007.72.003

Dunlap J (1999) Molecular bases for circadian clocks. Cell 96:271-290

Eckel-Mahan KL, Patel VR, Mohney RP et al (2012) Coordination of the transcriptome and metabolome by the circadian clock. Proc Natl Acad Sci USA 109:5541-5546. doi:10.1073/pnas.1118726109

Falchi F, Cinzano P, Elvidge CD et al (2011) Limiting the impact of light pollution on human health, environment and stellar visibility. J Environ Manag 92:2714-2722. doi:10.1016/j.jenvman.2011.06.029

Fonken LK, Nelson RJ (2014) The effects of light at night on circadian clocks and metabolism. Endocr Rev 35:648-670. doi:10.1210/er.20131051

Fonken LK, Bedrosian TA, Michaels HD et al (2012) Short photoperiods attenuate central responses to an inflammogen. Brain Behav Immun 26:617-622. doi:10.1016/j.bbi.2012.01.017

Fonken LK, Aubrecht TG, Meléndez-Fernández OH et al (2013a) Dim light at night disrupts molecular circadian rhythms and increases body 
weight. J Biol Rhythms 28:262-271

Fonken LK, Weil ZM, Nelson RJ (2013b) Mice exposed to dim light at night exaggerate inflammatory responses to lipopolysaccharide. Brain Behav Immun 34:159-163. doi:10.1016/j.bbi.2013.08.011

Foster RG, Kreitzmann L (2004) Rhythms of life: the biological clocks that control the daily lives of every living thing. Yale University Press, New Haven

Foster R, Follett B, Lythgoe J (1985) Rhodopsin-like sensitivity of extraretinal photoreceptors mediating the photoperiodic response in quail. Nature 313:50-52

Fuller RA, Warren PH, Gaston KJ (2007) Daytime noise predicts nocturnal singing in urban robins. Biol Lett 3:368-370. doi:10.1098/rsbl.2007.0134

Gaston KJ, Bennie J, Davies TW, Hopkins J (2013) The ecological impacts of nighttime light pollution: a mechanistic appraisal. Biol Rev 88:912-927. doi:10.1111/brv.12036

Gwinner E (1986) Circannual rhythms. Springer, Berlin Heidelberg, pp. 154.

Gwinner E (1989) Melatonin in the circadian system of birds: model of internal resonance. Circadian clocks and ecology. Hokkaido University Press, Sapporo, pp 127-145

Gwinner E (2003) Circannual rhythms in birds. In: Farner DS, King JR (eds) Curr Opin Neurobiol. Academic Press, New York and London, pp $770-778$

Gwinner E, Brandstätter R (2001) Complex bird clocks. Philos Trans R Soc B Biol Sci 356:1801-1810. doi:10.1098/rstb.2001.0959

Gwinner E, Hau M, Heigl S (1997) Melatonin: generation and modulation 
of avian circadian rhythms. Brain Res Bull 44:439-444

Halford S, Pires SS, Turton M et al (2009) VA opsin-based photoreceptors in the hypothalamus of birds. Curr Biol 19:1396-1402

IUCN (2012) World urbanization prospect: the 2011 revision

Kantermann T, Juda M, Vetter C, Roenneberg T (2010) Shift-work research: where do we stand, where should we go? Sleep Biol Rhythm 8:95-105

Karaganis SP, Kumar V, Beremand PD et al (2008) Circadian genomics of the chick pineal gland in vitro. BMC Genom 9:206. doi:10.1186/14712164-9-206

Kempenaers B, Borgström P, Loës P et al (2010) Artificial night lighting affects dawn song, extra-pair siring success, and lay date in songbirds. Curr Biol 20:1735-1739

Lesku JA, Rattenborg NC, Valcu M et al (2012) Adaptive sleep loss in polygynous pectoral sandpipers. Science 337:1654-1658.

doi:10.1126/science.1220939

Longcore T, Rich C, Mineau P et al (2013) Avian mortality at communication towers in the United States and Canada: which species, how many, and where? Biol Conserv 158:410-419. doi:10.1016/j.biocon.2012.09.019

Lucas RJ, Peirson SN, Berson DM et al (2014) Measuring and using light in the melanopsin age. Trends Neurosci 37:1-9.

doi:10.1016/j.tins.2013.10.004

Max M, McKinnon P, Seidenman K et al (1995) Pineal opsin: a nonvisual opsin expressed in chick pineal. Science 267:1502-1506. doi: $10.1126 /$ science. 7878470

Menaker M, Moreira LF, Tosini G (1997) Evolution of circadian 
organization in vertebrates. Braz J Med Biol Res 30:305-313

Metcalfe N, Monaghan P (201z3) Does reproduction cause oxidative stress? An open question. Trends Ecol Evol 166328, 347-350 AQ5

Miller MW (2006a) Apparent effects of light pollution on singing behavior of American robins. Condor 108:130. doi:10.1650/00105422(2006)108[0130:AEOLPO]2.0.CO;2

Miller MW (2006b) Apparent effects of light pollution on singing behavior of American robins. Condor 108:130-139. doi:10.1650/00105422(2006)108[0130:AEOLPO]2.0.CO; please delete this reference 2

Nordt A, Klenke R (2013) Sleepless in town-drivers of the temporal shift in dawn song in urban European blackbirds. PLoS One 8:e71476. doi:10.1371/journal.pone.0071476

Panda S, Antoch MP, Miller BH et al (2002) Coordinated transcription of key pathways in the mouse by the circadian clock. Cell 109:307-320. doi:10.1016/S0092-8674(02)00722-5

Partecke J, Van't Hof TJ, Gwinner E (2005) Underlying physiological control of reproduction in urban and forest-dwelling European blackbirds Turdus merula. J Avian Biol 36:295-305

Patel VR, Eckel-Mahan K, Sassone-Corsi P, Baldi P (2012) CircadiOmics: integrating circadian genomics, transcriptomics, proteomics and metabolomics. Nat Methods 9:772-773. doi:10.1038/nmeth.2111

Peirson SN, Halford S, Foster RG (2009) The evolution of irradiance detection: melanopsin and the non-visual opsins. Philos Trans R Soc B Biol Sci 364:2849-2865. doi:10.1098/rstb.2009.0050

Rajaratnam SM, Arendt J (2001) Health in a 24-h society. Lancet 358:999-1005. doi:10.1016/S0140-6736(01)06108-6 
Rattenborg NC, Voirin B, Vyssotski AL et al (2008) Sleeping outside the box: electroencephalographic measures of sleep in sloths inhabiting a rainforest. Biol Lett 4:402-405

Rich C, Longcore T (2006) Ecological consequences of artificial night lighting. 459Island Press, Washington (DC), USA, pp. 459

Rowan W (1938) Light and seasonal reproduction in animals. Biol Rev 13: $374-401$

Schaper SV, Dawson A, Sharp PJ et al (2012) Individual variation in avian reproductive physiology does not reliably predict variation in laying date. Gen Comp Endocrinol 179:53-62. doi:10.1016/j.ygcen.2012.07.021

Schlicht L, Valcu M, Loes P et al (2014) No relationship between female emergence time from the roosting place and extrapair paternity. Behav Ecol 25:650-659. doi:10.1093/beheco/aru035

Schoech SJ, Bowman R, Reynolds SJ (2004) Food supplementation and possible mechanisms underlying early breeding in the Florida Scrub-Jay (Aphelocoma coerulescens). Horm Behav 46:565-573

Schoech SJ, Rensel MA, Bridge ES et al (2009) Environment, glucocorticoids, and the timing of reproduction. Gen Comp Endocrinol 163:201-207. doi:10.1016/j.ygcen.2008.09.009

Schoech SJ, Bowman R, Hahn TP et al (2013) The effects of low levels of light at night upon the endocrine physiology of western scrub-jays (Aphelocoma californica). J Exp Zool A 319:527-538. doi:10.1002/jez.1816

Spoelstra K, van Grunsven RHA, Donners M et al (2015) Experimental illumination of natural habitat - direct and indirect ecological consequences of artificial light of different spectral composition. Philos Trans R Soc Lond Ser B 
Storch K-F, Lipan O, Leykin I et al (2002) Extensive and divergent circadian gene expression in liver and heart. Nature 417:78-83. doi:10.1038/nature744

Thomas DW, Blondel J, Perret P et al (2001) Energetic and fitness costs of mismatching resource supply and demand in seasonally breeding birds. Science 291:2598-2600

Titulaer M, Spoelstra K, Lange CYMJG, Visser ME (2012) Activity patterns during food provisioning are affected by artificial light in free living great tits (Parus major). PLoS One 7:e37377

Tsutsui K, Ubuka T, Yin H et al (2006) Mode of action and functional significance of avian gonadotropin-inhibitory hormone (GnIH): a review. J Exp Biol 305A:801-806. doi:10.1002/jez.a

Wikelski M, Martin LB, Scheuerlein A et al (2008) Avian circannual clocks: adaptive significance and possible involvement of energy turnover in their proximate control. Philos Trans R Soc B Biol Sci 363:411. doi:10.1098/rstb.2007.2147

Wyse C, Hazlerigg DG (2009) Seasonal biology: avian photoreception goes deep. Curr Biol 19:R685-R687. doi:10.1016/j.cub.2009.07.036

Xie L, Kang H, Xu Q et al (2013) Sleep drives metabolite clearance from the adult brain. Science 342:373-377. doi:10.1126/science.1241224 